\title{
Effects of Anti-Calcitonin Gene-Related Peptide for Migraines: A Systematic Review with Meta-Analysis of Randomized Clinical Trials
}

\author{
I-Hsin Huang ${ }^{1,2,+}$, Po-Chien Wu ${ }^{1,+}{ }^{+}$En-Yuan Lin ${ }^{3}$, Chien-Yu Chen ${ }^{2,4,5, * \mathbb{D} \text { and Yi-No Kang }}{ }^{6, *}$ (i) \\ 1 School of Medicine, College of Medicine, Taipei Medical University, Taipei 110, Taiwan \\ Department of Education, Taipei Medical University Hospital, Taipei 110, Taiwan \\ Division of Neurosurgery, Department of Surgery, Taiwan Adventist Hospital, Taipei 105, Taiwan \\ 4 Department of Anesthesiology, School of Medicine, College of Medicine, Taipei Medical University, \\ Taipei 110, Taiwan \\ 5 Department of Anesthesiology, Taipei Medical University Hospital, Taipei 110, Taiwan \\ 6 Evidence-Based Medicine Center, Wan Fang Hospital, Taipei Medical University, Taipei 116, Taiwan \\ * Correspondence: jc2jc@tmu.edu.tw (C.-Y.C.); academicnono@gmail.com (Y.-N.K.); \\ Tel.: +886-22-736-1661 (ext. 3107) (C.-Y.C.); +886-22-737-2181 (ext. 3759) (Y.-N.K.) \\ + These authors contributed equally to this work.
}

Received: 4 June 2019; Accepted: 16 July 2019; Published: 18 July 2019

\begin{abstract}
We aimed to evaluate the response rate of migraines by using anti-calcitonin gene-related peptide (anti-CGRP) for patients with migraines. We searched three main medical databases up to 29 March 2019. No restriction on language and publication time were applied. Eligible trials included randomized clinical trials investigating a $50 \%, 75 \%$, and $100 \%$ response rate of migraine patients after anti-CGRP intervention. The collected data were dichotomous, and risk ratios (RRs) with a $95 \%$ confidence interval (CI) were used to present the quantitative synthesis results. The systematic review identified 16 eligible randomized clinical trials (RCTs) with 9439 patients. Eight of the 16 trials with 2516 patients reported a 50\% response rate, and the pooled results showed a significant benefit from anti-CGRP. However, the effects seem to gradually reduce from the first month (RR 1.99, 95\% CI 1.59 to 2.49 ) to the third month (RR $1.48,95 \%$ CI 1.26 to 1.75) of treatment. The magnitude of effect was influenced by the type of anti-CGRP, according to the test for differences between subgroups (I-square $=53 \%$ ). The funnel plots and Egger's tests did not show serious small study effects in the results. In conclusion, the current evidences confirmed that anti-CGRP treatment can reduce migraine pain in the short term (within three months), but the long-term effect should be investigated in the future. Moreover, its effects may be influenced by the type and dose of anti-CGRP. Therefore, future studies should make direct comparisons among anti-CGRP medications.
\end{abstract}

Keywords: migraine; anti-calcitonin gene-related peptide; internal medicine

\section{Introduction}

Migraine is a highly prevalent, disabling neurological disorder with many socioeconomic and personal impacts [1]. It is characterized by headache, which is often accompanied with nausea, vomiting, photophobia, or prodromal and postdromal symptoms [1-3]. Migraine has become a main leading cause of disability [4]. Besides traditional acute migraine medications, anti-calcitonin gene-related peptide (anti-CGRP) medication has recently been developing as a new emerging treatment. 
There are mainly two theories to explain the mechanism of migraine: The central neuronal theory and the vascular theory [5]. CGRP, a 37-amino acid neuropeptide, plays an important role in migraine pathophysiology. CGRP is a highly potent vasodilator in the trigeminovascular system, exacerbating vasodilation while causing neurogenic inflammation $[5,6]$. Nowadays, preventive treatment of migraine is mostly non-specific migraine medications and has had substantial adverse events, which may increase the non-adherence rate and controversial efficacy of the treatment [7]. Therefore, a migraine-specific, effective, well-tolerated medication is needed as a better preventive treatment.

Accordingly, human monoclonal antibodies acting as CGRP antagonists, such as Erenumab (AMG334), Eptinezumab (ALD403), Galcanezumab (LY2951742), and Fremanezumab (TEV48125), were developed to be an option of acute migraine treatment [8]. Several randomized clinical trials assessed the efficacy and safety of CGRP antagonists for chronic or episodic migraine. In the past two years, those trials reported their results at many conferences [9-38], and the full reports were recently published. Primary endpoints in these randomized clinical trials usually included a response rate of migraine days, monthly migraine day, and monthly headache day. Secondary endpoints included the usage times of migraine-specific medication, cumulative hours of headache, Headache Impact Test 6 (HIT-6) score, and Migraine Specific Quality of Life Questionnaire (MSQ) score. All the trials indicated better outcomes and prevention of migraine with anti-CGRP medication, but the efficacy seemed to be diversified by the different interval and period of drug administration [39-64]. Though the synthesized evidences consistently confirmed that anti-CGRP had no serious adverse events reported and the effects of anti-CGRP remain controversial due to differences in follow-up and the percentage of response rate [65-69]. Some previous meta-analyses and systematic reviews analyzed a small amount of the trials $[67,68]$, and one article containing a larger amount of trials showed results with large heterogeneity by estimated analysis due to the variety of features and units of different trials [65]. A bigger synthesis pooling of more than 2500 cases showed that anti-CGRP had significantly better outcomes than placebo in the change of migraine days from baseline to the third month, but the insufficient evidence on the $100 \%$ responder rate was not statistically significant [66]. Additionally, there are several ongoing trials that should be updated. Consequently, our systematic review and meta-analysis aims to update the evidence of the effects of anti-CGRP for migraine by synthesizing the current randomized clinical trials.

\section{Results}

A total of 1089 studies were identified from the three important biomedical databases, in which 476 were duplicated. In the remaining 613 studies, 582 were removed after title, abstract, and article type screening because of irrelevance $(n=128)$, non-RCT study $(n=209)$, or gray literatures without details $(n=245)$. Then, we retrieved the full-text of the 31 remaining studies for further review. One study met the exclusion criteria and was removed [9]. Finally, the eligible studies were checked for data sources and they were found to be from 16 RCTs. These trials were included in this study for qualitative and quantitative synthesis [39-50,52-64]. The flow diagram of evidence selection is presented in Figure 1. 


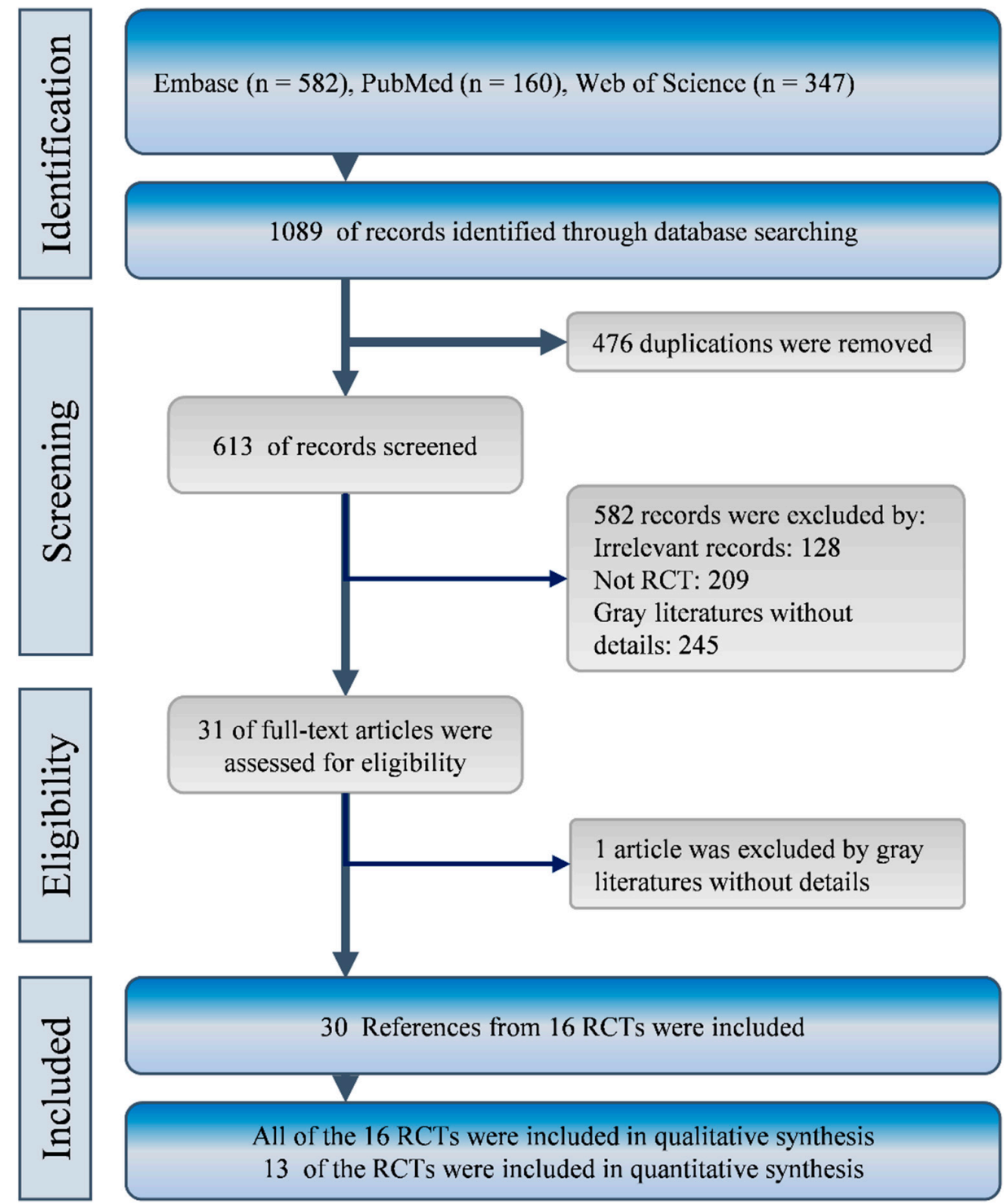

Figure 1. Flow diagram of study selection.

\subsection{Characteristics and Quality of Included Studies}

The 16 included RCTs recruited 9439 patients with migraine from Argentina, Canada, Europe, Israel, Korea, Mexico, Russia, Taiwan, Turkey, and the USA between July 2012 and October 2017. Table 1 presents characteristics of each trial. These trials gave anti-CGRP for at least 12 weeks, and the longest treatment duration was 52 weeks. The trials completed a follow-up of at least four weeks, and the longest follow-up duration was four months. Eleven trials focused on episodic migraine, and four trials investigated chronic migraine. The other one recruited both populations of episodic migraine and chronic migraine. These trials did not set criteria for aura (Table S1). The age of patients ranged from 18 to 70 years old. Most of the patients were females $(n=7992 ; 84.67 \%)$, and there were only 1447 males $(15.33 \%)$. Most trials in this systematic review and meta-analysis presented a low selection bias, performance bias, attrition bias, and reporting bias (Table S2).

\subsection{Monthly $50 \%$ Response Rate}

Out of the 16 RCTs, eight trials reported data of the monthly 50\% response rate (Figure 2) [39-45, $48,50,53,57,58,64]$. According to the data from 2516 patients, anti-CGRP led to a significantly higher $50 \%$ response rate when compared with placebo (RR 1.99, 95\% CI 1.59 to 2.49 ) in the first month. In the 
second month, anti-CGRP also resulted in a significantly higher 50\% response rate $(649 / 1476 ; 43.97 \%)$ than placebo (269/1034; 26.02\%) with RR 1.66 (95\% CI 1.40 to 1.96). Similarly, anti-CGRP showed a significantly higher $50 \%$ response rate $(778 / 1713 ; 45.42 \%)$ than placebo $(409 / 1302 ; 31.41 \%)$ with RR 1.48 (95\% CI 1.26 to 1.75 ) in the third month. Although the anti-CGRP showed a better $50 \%$ response rate without small study effects (Table 2 and Figure S1-S3), a slightly decreasing trend could be observed from the first month (RR 1.99), to the second month (RR 1.66) and the third month (RR 1.48). The test for subgroup differences also reflected a high heterogeneity among the three subsets (I-square $=53.3 \%$ ). Furthermore, the heterogeneity in these outcomes reached the threshold (I-square $=50 \%$ ), and the effect of heterogeneity should be concerning. Thus, subset analysis was applied to explore the source of heterogeneity.

The subset analysis of drugs decreased heterogeneity from I-square $55 \%$ to $40.42 \%$ in the first month, from $50 \%$ to $49.38 \%$ in the second month, and from $67 \%$ to $31.79 \%$ in the third month (Table 2 and Figure S4-S6). The results of the subset analysis still confirmed the effect of anti-CGRP medications on migraine, except for Eptinezumab in the third month. The effect of Eptinezumab on migraine in the third month should be further tested in the future because the only available RCT for our review consisted of a small sample size $(n=151)$.

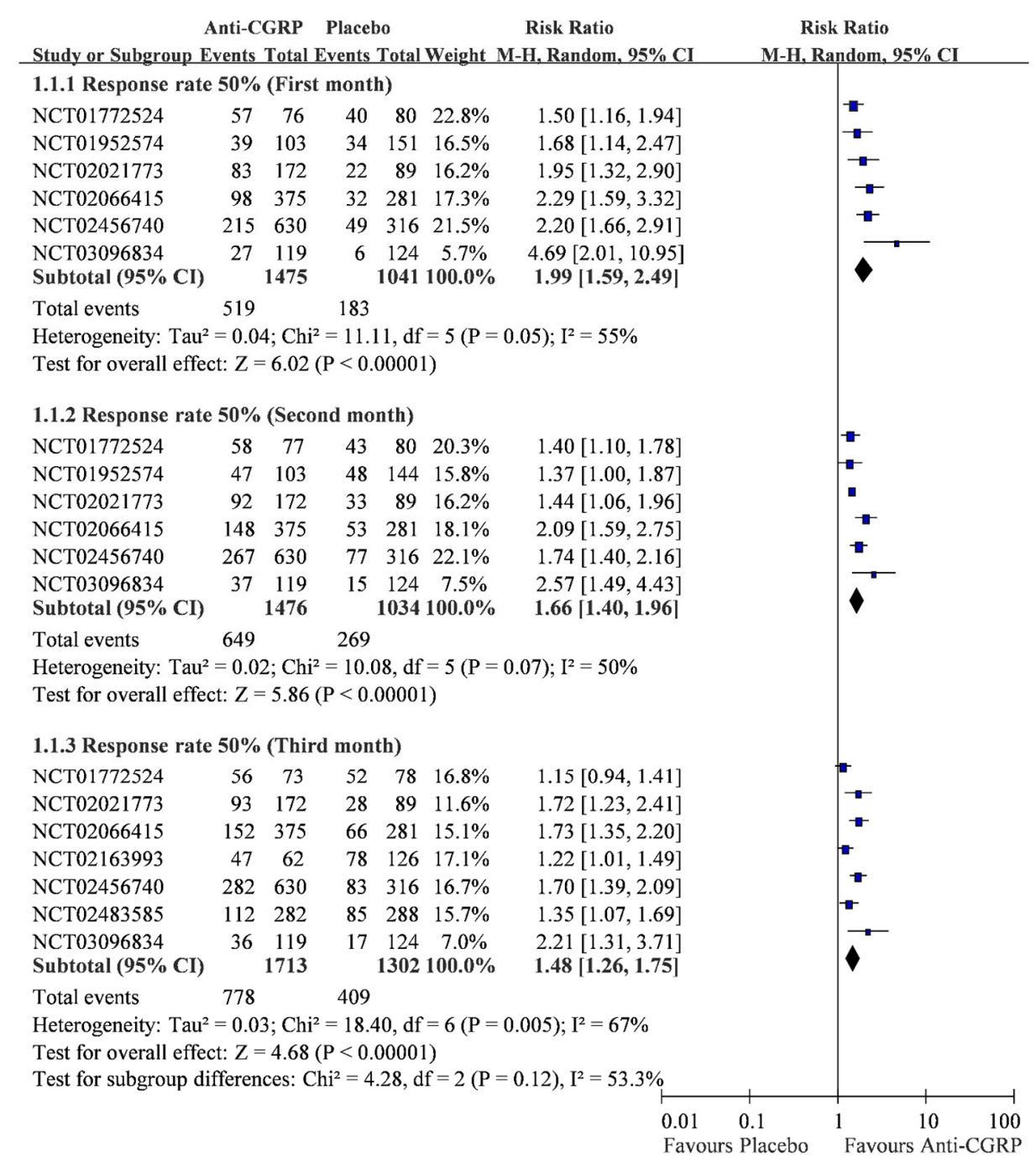

Figure 2. The $50 \%$ reduction rate of anti-CGRP and placebo. 
Table 1. Characteristics of the included randomized controlled trials.

\begin{tabular}{|c|c|c|c|c|c|c|}
\hline Trial & Area & Recruitment Duration & Medication & Patients $(n)$ & Age & Male/Female \\
\hline NCT01772524 [39] & USA & Jan. 28, $2013 \sim$ Dec. 23, 2013 & Eptinezumab 1000 mg/placebo & 163 & $18-55$ & $30 / 133$ \\
\hline NCT02456740 [40,57] & $\begin{array}{l}\text { Canada, Europe, } \\
\text { Turkey, USA }\end{array}$ & Jul. $2015 \sim$ Sep. 5, 2016 & Erenumab $70 \mathrm{mg} / 140 \mathrm{mg} /$ placebo & 955 & $18-65$ & $141 / 814$ \\
\hline NCT01952574 [41,44] & Canada, Europe, USA & Aug. 6, $2013 \sim$ June 30, 2014 & Erenumab $7 \mathrm{mg} / 21 \mathrm{mg} / 70 \mathrm{mg} /$ placebo & 483 & $18-60$ & $94 / 389$ \\
\hline NCT02066415 [42,43,57] & Canada, Europe, USA & Apr. 3, $2014 \sim$ Dec. 4, 2015 & Erenumab $70 \mathrm{mg} / 140 \mathrm{mg} /$ placebo & 667 & $18-65$ & $115 / 552$ \\
\hline NCT02483585 [45] & Canada, Europe, USA & Jul. $2015 \sim$ Jul. 2016 & Erenumab $70 \mathrm{mg} /$ placebo & 577 & $18-65$ & $85 / 492$ \\
\hline NCT03096834 [58] & Australia, Europe & Mar. 20, 2017 Oct. 27, 2017 & Erenumab $140 \mathrm{mg} /$ placebo & 246 & $18-65$ & $46 / 200$ \\
\hline NCT02629861 [46] & $\begin{array}{l}\text { Canada, Europe, } \\
\text { Russia, USA }\end{array}$ & Mar. 23, $2016 \sim$ Apr. 10, 2017 & $\begin{array}{l}\text { Fremanezumab } 225 \mathrm{mg} \text { monthly/ } 3.225 \mathrm{mg} \\
\text { single higher dose/placebo }\end{array}$ & 875 & $18-70$ & $133 / 742$ \\
\hline NCT02621931 [47] & USA & Mar. 2016 Jan. 2017 & $\begin{array}{c}\text { Fremanezumab } 675 \mathrm{mg}+2 \cdot 225 \mathrm{mg} / 675 \mathrm{mg}+ \\
\text { 2.placebo/placebo }\end{array}$ & 1130 & $18-70$ & 139/991 \\
\hline NCT02021773 [48-51] & USA & Jan. $2014 \sim$ Dec. 2014 & Fremanezumab 900 mg/675-225 mg/placebo & 263 & $18-65$ & $37 / 226$ \\
\hline NCT02025556 [59] & USA & Jan. $2014 \sim$ Jan. 2015 & Fremanezumab $675 \mathrm{mg} / 225 \mathrm{mg} /$ placebo & 297 & $18-65$ & $36 / 261$ \\
\hline NCT02614183 [52,60,61] & Canada, USA & Jan. 11, $2016 \sim$ Mar. 22, 2017 & Galcanezumab 120 mg/240 mg/placebo & 858 & $18-65$ & $140 / 818$ \\
\hline NCT02163993 [53,56,64] & USA & July 7, $2014 \sim$ Aug. 19, 2015 & $\begin{array}{l}\text { Galcanezumab } 5 \mathrm{mg} / 50 \mathrm{mg} / 120 \mathrm{mg} / \\
\quad 300 \mathrm{mg} / \text { placebo }\end{array}$ & 410 & $18-65$ & $70 / 340$ \\
\hline NCT01625988 [55] & USA & July 31, $2012 \sim$ Sep. 18, 2013 & Galcanezumab $150 \mathrm{mg} /$ placebo & 217 & $18-65$ & $33 / 184$ \\
\hline NCT02614196 [54,60,61] & $\begin{array}{c}\text { Argentina, Europe, } \\
\text { Israel, Korea, Mexico, } \\
\text { Taiwan, USA }\end{array}$ & Jan. $2016 \sim$ Mar. 2017 & Galcanezumab 120 mg/240 mg/placebo & 915 & $18-65$ & $134 / 781$ \\
\hline NCT02614261 [61,62] & $\begin{array}{c}\text { Argentina, Canada, } \\
\text { Europe, Israel, } \\
\text { Mexico, Taiwan, USA }\end{array}$ & Jan. $2016 \sim$ Mar. 2017 & Galcanezumab 120 mg/240 mg/placebo & 1113 & $18-65$ & $167 / 946$ \\
\hline NCT02614287 [63] & Canada, Europe, USA & Dec. $2015 \sim$ Sep. 2017 & Galcanezumab $120 \mathrm{mg} / 240 \mathrm{mg} /$ placebo & 270 & $18-65$ & $47 / 223$ \\
\hline
\end{tabular}


Table 2. Summary of further analysis.

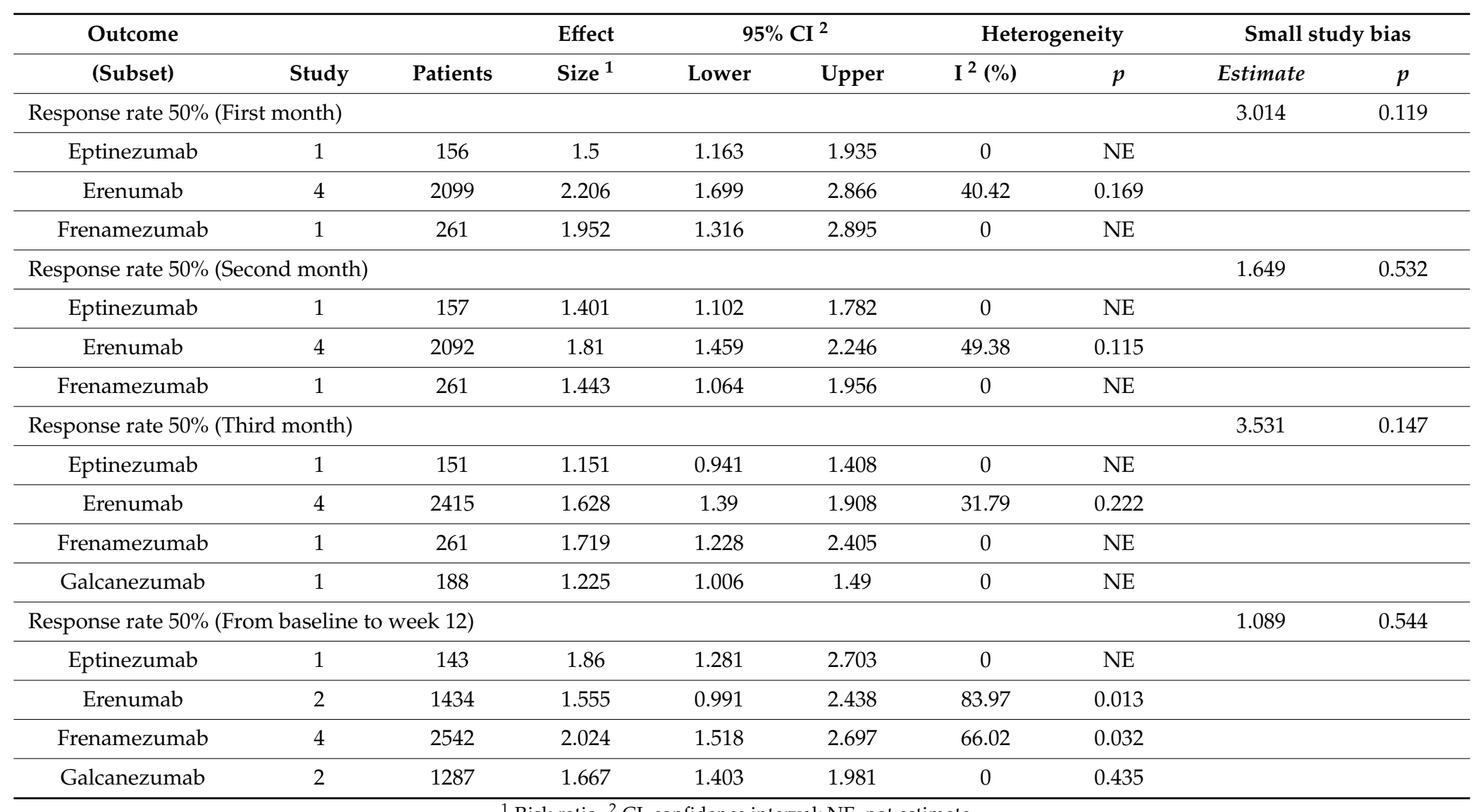

${ }^{1}$ Risk ratio. ${ }^{2} \mathrm{CI}$, confidence interval; NE, not estimate. 


\subsection{Cumulative Response Rate within Three Months}

A total of nine RCTs presented a cumulative response rate within three months [39,41-44,46$50,55,57,59,61,62]$. These trials recruited 5406 cases, and the pooled results are shown in Figure 3. The anti-CGRP $(1272 / 3262 ; 38.99 \%)$ had a significantly higher rate in a $50 \%$ cumulative reduction of migraine within three months when it was compared with placebo $(460 / 2144 ; 21.46 \%)(\mathrm{RR} 1.78,95 \% \mathrm{CI}$ 1.54 to 2.05$)$. Similarly, the pooled result indicated that anti-CGRP $(259 / 1641 ; 15.78 \%)$ had significantly higher rates in the $75 \%$ response within three months than placebo (93/1339; 6.95\%) (RR 2.34, 95\% CI 1.77 to 3.09). For the $100 \%$ response rate within three months, the pooled result also showed that anti-CGRP $(59 / 1075 ; 5.49 \%$ ) was significantly higher than placebo $(23 / 911 ; 2.52 \%$ ) (RR 2.07, 95\% CI 1.29 to 3.32). Egger's test did not reflect a small study effect on these results (Table 2 and Figure S7-S9). Low heterogeneities were detected in the results of the $75 \%$ response rate (I-square $=26 \%$ ) and $100 \%$ response rate (I-square $=2 \%$ ), but the $50 \%$ response rate still had a high heterogeneity (I-square $=56 \% ; p<0.10$ ). Although this study tried to reduce the heterogeneity by stratifying the anti-CGRP medications, the heterogeneity was not successfully reduced (Table 2). Unfortunately, the heterogeneity in the subset of Erenumab (I-square $=83.97 \% ; p<0.10$ ) and Frenamezumab (I-square $=66.02 \% ; p<0.10$ ) were still high (Table 2 and Figure S10-S12).

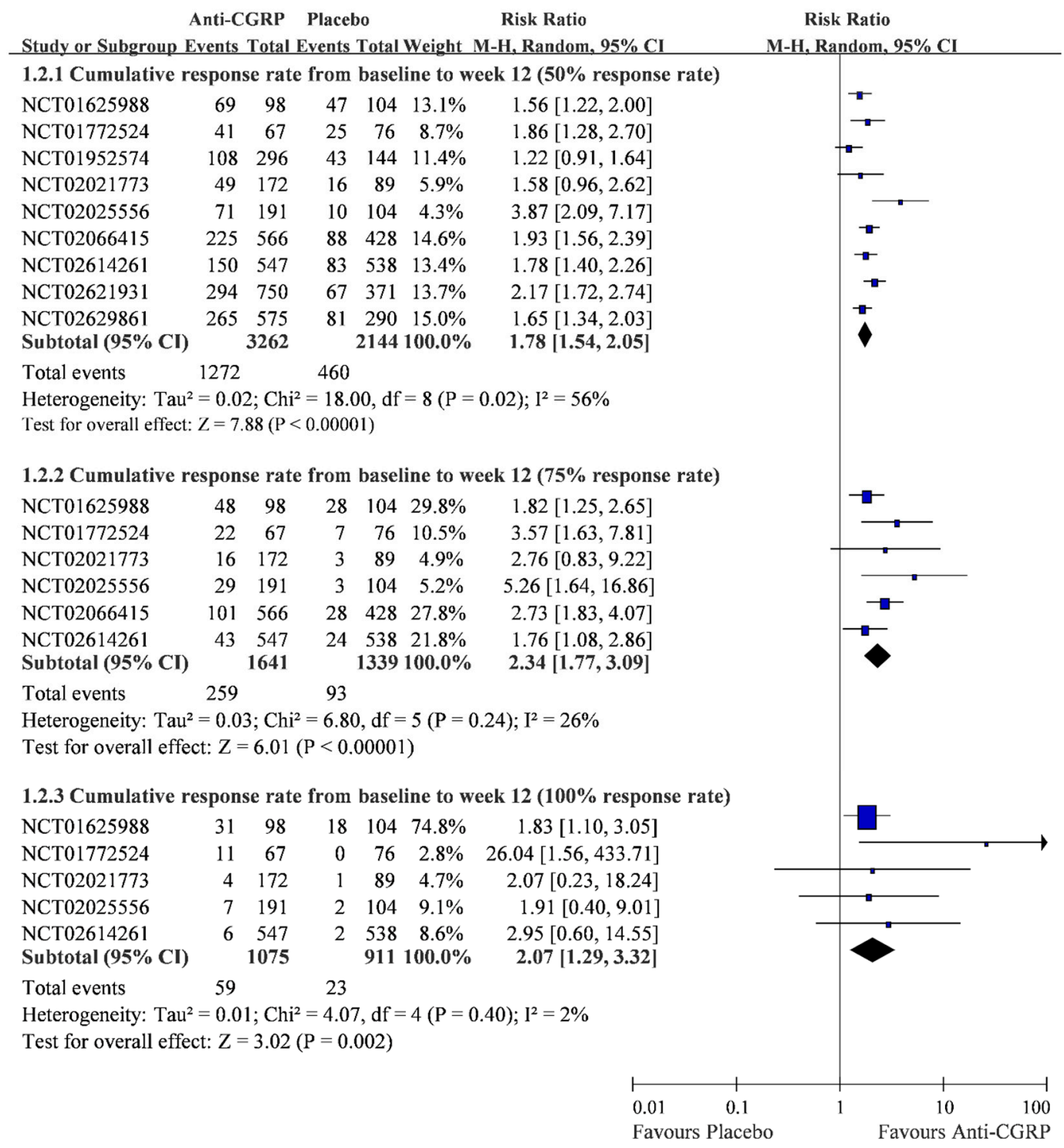

Figure 3. Cumulative response rate from the initial to the 12th month between anti-CGRP and placebo. 


\section{Discussion}

In this study, we synthesized 16 trials. Our data showed that, as compared with placebo, treatment with anti-CGRP medications was associated with a significant progressive decrease of the response rate of migraine days during the three-month period. Though the heterogeneity is low in the overall three-month analysis data, the I-square is quite high (51.4\%), reflecting the differences between months and types of anti-CGRP medications. According to the Figure 2, the efficacy of medications decreased through time, showing a slightly descending trend. Moreover, there was an individual difference in each four types of the anti-CGRP medications. Among them, Frenamezumab had the least efficacy. In other words, anti-CGRP medications showed effective results in treating migraine, but the efficacy may be dependent on the time and types of medications used.

The neuropeptide calcitonin gene-related peptide acts as a significant biomarker in the trigeminovascular system. Initially, an oral CGRP inhibitor, geptan, was developed to prevent migraine, but the trials of geptan were terminated due to liver toxicity. Another anti-CGRP medication, fully human monoclonal antibody, was developed alternatively [8]. Three monoclonal antibodies, including galcanezumab, fremanezumab, and eptinezumab, bind to become an isoform of CGRP, preventing CGRP from binding to its receptor and activating the pathway of vasodilation and inflammation $[47,70]$. The other monoclonal antibody, erenumab, binds to CGRP receptors directly and can also prevent the activation of trigeminal fibers $[40,70]$. Since the pharmacological properties of these monoclonal antibodies are different, they lead to a various efficacy of migraine control and prevention. The characteristics among these anti-CGRP can vary from target selection (CGRP or CGRP receptor), mechanism of immune activation, pharmacokinetics, and bioavailability.

Among three antibodies that bind to become an isoform of CGRP, Eptinezumab, Galcanezumab, and Fremanezumab are Immunoglobulin G1 (IgG1)antibody, IgG4 antibody, and IgG2 antibody, respectively [39,47,70,71]. Erenumab is an IgG2 antibody and competitively binds to CGRP receptors $[40,70]$. Additionally, only Eptinezumab is given in intravenous (IV) form, while the others are subcutaneous injection [72]. According to our results, subcutaneous injection of IgG2 antibody, Fremanezumab, performed with the least efficacy among four anti-CGRP medications. Another possible reason to explain the variety of efficacy is that Fremanezumab has the longest half-life among the four antibodies, ranging from 31 to 39 days [70,73,74]. However, further studies are warranted to evaluate the pharmacokinetic comparison of anti-CGRP medication to explain why Fremanezumab had less efficacy than the other monoclonal antibodies.

Anti-CGRP medications have a unique mechanism toward the suppression of migraine pain in comparison to traditional migraine therapy. Anti-CGRP medications, as fully human monoclonal antibodies, selectively bind to CGRP receptors to prevent activation of trigeminal fibers from vasodilation and inflammation. On the other hand, traditional migraine medication therapy, including triptans, ergotamines, acetaminophen, and non-steroidal anti-inflammatory drugs, aims to block 5HT-1B and 5HT-1D receptors or prevent inflammatory substances from producing via the COX pathway, which often lead to adverse effects due to systemic action of these pathways. Current studies have shown that traditional migraine therapy might correlate with a deterioration of the patient's symptoms. Though it has not been fully proved yet, anti-CGRP medications are an expecting and rising therapy in reducing the number of pain days, promoting quality of life, and even preventing pain from happening in patients with migraine.

\section{Comparison to the Previous Syntheses}

The previous five syntheses on this topic concluded that anti-CGRP is effective and safe, yet these evidences did not completely mention the effects in each month [65-69]. Three of these syntheses involved cases of more than $2500[65,66,69]$, and the other two pooled limited data that amounted to fewer than 1000 cases $[67,68]$. One of the three syntheses with a bigger sample size did not conduct quantitative synthesis [69]. The other two of the three syntheses provided stronger evidence on the effects of anti-CGRP for migraine by identifying more evidences on this topic. Interestingly, one of 
the two meta-analyses included eight trials in April 2018, and the last updated meta-analysis only included five trials using similar criteria in July 2018. Although the two meta-analyses made similar conclusions, the meta-analysis with the bigger sample size reported heterogeneous results. The sources of the heterogeneities should be explored, yet the previous analysis did not successfully identify the sources of the heterogeneities.

The present meta-analysis improved evidence on this topic by identifying 16 trials with 9439 patients with migraine, synthesizing more cases, and pointing out the potential sources of heterogeneities. The pooled results on the response rate of migraine were based on at least 2500 cases, and the result of the $50 \%$ cumulative response rate was based on 5406 cases. This pooling gave a clear picture of the efficacy of anti-CGRP on migraine, and no evidence detected small study effects on the results. Moreover, the present quantitative syntheses for the response rate were successfully reduced heterogeneities (I-square $<50 \%$ ). That is to say, the present meta-analysis is more confident and informative than previous syntheses.

\section{Methods}

This is a prospective systematic review starting from 28 November 2018, and study protocol was written beforehand. The primary design was registered on PROSPERO (CRD42018118063). The research team involved a neurologist, an anesthesiologist, and an experienced researcher in systematic review and meta-analysis [75-77]. The neurologist and anesthesiologist also have experience on conducting systematic reviews and meta-analyses [78,79]. The authors conducted this study according to the PRISMA guidelines in evidence selection, quality assessment, evidence synthesis, and research reporting [80].

\subsection{Data Source and Search}

Basic eligible criteria for evidence selection was defined before a comprehensive search was conducted. The inclusion criteria were as follows: (1) Studies recruiting patients with migraine, and (2) studies evaluating the outcomes of patients who received treatment with anti-CGRP medications. According to these criteria, the relevant terms of migraine, Eptinezumab, Erenumab, Galcanezumab, and Fremanezumab, in free-text, medical subject headings (MeSH in PubMed and Emtree in EMBASE), and abbreviations were used for the literature search. The keywords were combined by appropriate Boolean operators, and formed a primary search strategy without limitations on the language and publish data. The primary search strategy was done with PubMed, and was adapted to the Cochrane Library (including Cochrane CENTERL), Embase, and Web of Science. The final search was completed on 29 March 2019 (Table S3).

\subsection{Study Selection}

After potential studies were identified, two authors ( $\mathrm{YHH}$ and BCW) rooted out irrelevant studies by screening the title and abstract according to the exclusion criteria. The exclusion criteria included: (1) Studies recruiting patients with diseases other than migraine, (2) studies mixing patients with general headache and migraine without stratification analysis, (3) studies using treatments other than anti-CGRP medication, (4) gray literature studies without details of patients' characteristics or results, and (5) studies that were not RCTs. The corresponding author (YNK) made the final judgement for study selection when the two authors had any disagreement.

\subsection{Data Extraction and Quality Assessment}

The two authors (YHH and BCW) also individually reviewed all selected RCTs for data extraction and risk of bias assessment. They extracted trial characteristics and outcome data. The characteristics involved trial registry number, country, recruitment duration, medication strategy, age range, and sex. The outcome data involved the $50 \%, 75 \%$, and $100 \%$ response rate of migraine. The risk of bias of the selected RCTs were assessed by using the Cochrane Risk of Bias Tool. This tool comprises seven 
methodological items, including: (1) Allocation generation, (2) allocation concealment, (3) blinding of participants and personnel, (4) blinding of outcome assessment, (5) incomplete outcome data, (6) selective report, and (7) other bias. The third author (YNK) made the final judgement for the risk of biased assessment.

\subsection{Data Synthesis and Analysis}

The quantitative synthesis in this study used the risk ratio (RR) for performing binary outcome analysis from the RCTs. This study chose the Mantel-Haenszel method for meta-analysis. Generally, the Mantel-Haenszel method is considered to be preferable to the inverse variance method. All the analyses were conducted using the random-effects model. The results are shown in the RR and 95\% confidence interval (CI).

To assess the quality of the pooling results, this study detected the heterogeneity and small study effect. I-square and the $p$-value of Cochran $\mathrm{Q}$ was used to assess heterogeneity. This study defined high heterogeneity as an I-square higher than $50 \%$ or the $p$-value of Cochran Q lower than 0.10 (a rigorous threshold for heterogeneity detection). To explore the source of heterogeneity, this quantitative synthesis conducted sensitivity analysis by using the subset design. The subset was stratified according to different types of drugs. A small study effect was illustrated using the funnel plot and calculated Egger's test. Pooled results were deemed affected by small study bias when the $p$-value of Egger's test lower than 0.05 .

\section{Limitations}

Although this systematic review and meta-analysis owned more advantages than previous syntheses, this study has three limitations. First, this meta-analysis cannot distinguish the effects from different dosages because the dosages among different types of anti-CGRP treatments cannot be converted easily. Dosage effects was also a limitation in the previous syntheses. Therefore, further studies should investigate dosage effects among different type of anti-CGRP treatments. Secondly, this meta-analysis did not synthesize the monthly migraine days, reduction of migraine days, monthly headache days, or reduction of headache days. This limitation may result in a lack of intuitive information (mean difference), but using the response rate can keep results unaffected by an extreme value. Moreover, response rates presenting the percentage of reduction in migraine days could be an index of the improvement. Thirdly, few evidences reported a $75 \%$ or $100 \%$ response rate each month. Thus, this meta-analysis cannot give a clear picture about how the anti-CGRP reaches a $75 \%$ or $100 \%$ response rate of migraine monthly. However, this study still proved an overview showing that the anti-CGRP is a highly effective treatment for migraine according to the cumulative $75 \%$ and $100 \%$ response rate.

\section{Conclusions}

In conclusion, the current evidences confirmed that anti-CGRP reduced migraine in the short term (within three months). The long-term effect should be investigated in the future. Moreover, its effects may be affected by the type and use of anti-CGRP. Therefore, future studies should make direct comparisons among the anti-CGRP medications.

Supplementary Materials: Supplementary materials can be found at http://www.mdpi.com/1422-0067/20/14/ $3527 / s 1$.

Author Contributions: Conceptualization: I.-H.H., P.-C.W. Data curation: I.-H.H., P.-C.W. Formal analysis: Y.-N.K. Investigation: I.-H.H., P.-C.W., C.-Y.C., Y.-N.K. Methodology: C.-Y.C., Y.-N.K. Supervision: E.-Y.L. Visualization: Y.-N.K. Writing—original draft: I.-H.H., P.-C.W. Writing—review and editing: E.-Y.L., C.-Y.C., Y.-N.K.

Funding: This research received no external funding.

Acknowledgments: We thank Cindy Chan for her insightful comments on an earlier draft of this manuscript and language editing. 
Conflicts of Interest: The authors declare no conflict of interest.

\section{Abbreviations}

$\begin{array}{ll}\text { Anti-CGRP } & \text { anti-calcitonin gene-related peptide } \\ \text { CI } & \text { confidence interval } \\ \text { RCT } & \text { randomized clinical trial } \\ \text { RR } & \text { risk ratio } \\ \text { SAW } & \text { single active warming strategy } \\ \text { SUCRA } & \text { surface under the cumulative ranking curve }\end{array}$

\section{References}

1. Headache Classification Committee of the International Headache Society (IHS) The International Classification of Headache Disorders, 3rd edition. Cephalalgia 2018, 38, 1-211. Available online: https://journals.sagepub.com/doi/10.1177/0333102417738202 (accessed on 17 July 2019). [CrossRef] [PubMed]

2. Saper, J.R. Diagnosis and symptomatic treatment of migraine. Headache 1997, 37, 1-14.

3. Martins-Oliveira, M.; Hoffmann, J.; Schankin, C.; Akerman, S.; Goadsby, P.J.; Holland, P.R. Pathophysiology of Migraine: A Disorder of Sensory Processing. Physiol. Rev. 2017, 97, 553-622. Available online: https://www.physiology.org/doi/full/10.1152/physrev.00034.2015 (accessed on 17 July 2019).

4. Naghavi, M.; Abajobir, A.A.; Abbafati, C.; Abbas, K.M.; Abd-Allah, F.; Abera, S.F.; Aboyans, V.; Adetokunboh, O.; Afshin, A.; Agrawal, A.; et al. Global, regional, and national age-sex specific mortality for 264 causes of death, 1980-2016: A systematic analysis for the global burden of disease study 2016. Lancet 2017, 390, 1151-1210. [CrossRef]

5. Ho, T.W.; Edvinsson, L.; Goadsby, P.J. CGRP and its receptors provide new insights into migraine pathophysiology. Nat. Rev. Neurol. 2010, 6, 573-582. [CrossRef] [PubMed]

6. Goadsby, P.J.; Edvinsson, L.; Ekman, R. Vasoactive peptide release in the extracerebral circulation of humans during migraine headache. Ann. Neurol. 1990, 28, 183-187. [CrossRef] [PubMed]

7. Silberstein, S.D.; Holland, S.; Freitag, F.; Dodick, D.W.; Argoff, C.; Ashman, E. Evidence-based guideline update: Pharmacologic treatment for episodic migraine prevention in adults: Report of the quality standards subcommittee of the american academy of neurology and the american headache society. Neurology 2012, 78, 1337-1345. [CrossRef]

8. Tso, A.R.; Goadsby, P.J. Anti-CGRP Monoclonal Antibodies: The Next Era of Migraine Prevention? Curr. Treat. Options Neurol. 2017, 19, 27. [CrossRef]

9. Ashina, M.; Brandes, J.L.; Katsarava, Z.; Lipton, R.B.; Pascual, J.; Palmer, K.; Desai, P.; Picard, H.; Mikol, D.D.; Lenz, R.A. Patient-reported outcomes from the arise trial: A phase 3, randomized, double-blind study of erenumab in subjects with episodic migraine. Headache 2017, 57, 192.

10. Ashina, M.; Dodick, D.; Kudrow, D.; Lanteri-Minet, M.; Osipova, V.; Palmer, K.; Picard, H.; Mikol, D.; Lenz, R. A phase 3, randomized, double-blind, placebo-controlled study to evaluate the efficacy and safety of erenumab in migraine prevention: Primary results of the arise trial. Eur. J. Neurol. 2017, 24, 470. Available online: https://onlinelibrary.wiley.com/doi/epdf/10.1111/ene.13368 (accessed on 17 July 2019).

11. Buse, D.C.; Lipton, R.B.; Mikol, D.D.; Thach, A.V.; Desai, P.; Picard, H.; Kubo, Y.; Hareendran, A.; Kawata, A.K. Reducing the impact of migraine on functioning: Results from the strive trial: A phase 3, randomized, double-blind study of erenumab in subjects with episodic migraine. Cephalalgia 2017, 37, 195-196.

12. Dodick, D.; Ashina, M.; Kudrow, D.; Lanteri-Minet, M.; Osipova, V.; Palmer, K.; Picard, H.; Mikol, D.D.; A Lenz, R. A phase 3, randomised, double-blind, placebo-controlled study to evaluate the efficacy and safety of erenumab in migraine prevention: Primary results of the arise trial. J. Neurol. Neurosurg. Psychiatry 2017, 88, e1. [CrossRef]

13. Dodick, D.; Goadsby, P.; Silberstein, S.; Lipton, R.; Hirman, J.; Smith, J. Randomized, double-blind, placebo-controlled trial of ald403, an anti-cgrp peptide antibody in the prevention of chronic migraine. Neurology 2017, 88, S52-003. 
14. Dodick, D.W.; Ashina, M.; Kudrow, D.; Lanteri-Minet, M.; Osipova, V.; Palmer, K.; Picard, H.; Mikol, D.D.; Lenz, R.A. A phase 3, randomized, double-blind, placebo-controlled study to evaluate the efficacy and safety of erenumab in migraine prevention: Primary results of the arise trial. Headache 2017, 57, 191-192. Available online: https://headachejournal.onlinelibrary.wiley.com/doi/abs/10.1111/head.13102 (accessed on 17 July 2019).

15. Goadsby, P.; Reuter, U.; Bonner, J.; Broessner, G.; Hallstrom, Y.; Zhang, F.; Sapra, S.; Picard, H.; Mikol, D.; Lenz, R. Phase 3, randomized, double-blind, placebo-controlled study to evaluate the efficacy and safety of erenumab (amg 334) in migraine prevention: Primary results of the strive trial. Neurology 2017, 89, e104. Available online: https://doi.org/10.1212/WNL.0000000000004380 (accessed on 17 July 2019).

16. Goadsby, P.J.; Reuter, U.; Bonner, J.; Broessner, G.; Hallstrom, Y.; Zhang, F.; Sapra, S.; Picard, H.; Mikol, D.D.; Lenz, R. A Phase 3, randomized, double-blind, placebo-controlled study to evaluate the efficacy and safety of erenumab (amg 334) in migraine prevention: Primary results of the strive trial. Headache 2017, 57, 128-129. Available online: https://headachejournal.onlinelibrary.wiley.com/doi/abs/10.1111/head.13102 (accessed on 17 July 2019).

17. Hareendran, A.; Buse, D.C.; Lipton, R.B.; Bayliss, M.S.; Mikol, D.D.; Revicki, D.A.; Zhang, F.; Desai, P.; Picard, H.; Kawata, A.K. Reducing impaired days: Results from the strive trial, a phase 3, randomised, double-blind study of erenumab for episodic migraine. J. Headache Pain 2017, 18, 275-276.

18. Goadsby, P.J.; Reuter, U.; Bonner, J.; Broessner, G.; Hallstrom, Y.; Zhang, F.; Sapra, S.; Picard, H.; Mikol, D.; Lenz, R. Phase 3, randomised, double-blind, placebo-controlled study to evaluate the efficacy and safety of erenumab (amg 334) in migraine prevention: primary results of the strive trial. J. Neurol. Neurosurg. Psychiatry 2017, 88, e1. Available online: https://jnnp.bmj.com/content/88/5/e1.62 (accessed on 17 July 2019). [CrossRef]

19. Reuter, U.; Brandes, J.; Dolezil, D.; Tepper, S.; Cheng, S.; Leonardi, D.; Lenz, R.; Mikol, D. Efficacy of erenumab (amg 334) in patients with chronic migraine in north america and europe: Subgroup analysis of a phase 2, randomised, double-blind, placebo-controlled study. Eur. J. Neurol. 2017, 24, 548.

20. Smith, J.; Dodick, D.W.; Goadsby, P.J.; Silberstein, S.D.; Lipton, R.B.; Hirman, J. Randomized, double-blind, placebo-controlled trial of ald403 (eptinezumab), an anti-cgrp monoclonal antibody for the prevention of chronic migraine. Headache 2017, 57, 130.

21. Stauffer, V.; Skljarevski, V.; Zhang, Q.; Ford, J.H.; Carter, J.; Aurora, S.K. The relationship between headache frequency and illness burden prior to treatment randomization in two phase 3 episodic migraine clinical trials. Headache 2017, 57, 190.

22. Tepper, S.; Lipton, R.; Reuter, U.; Silberstein, S.; Stewart, W.; Leonardi, D.; Desai, P.; Cheng, S.; Mikol, D.; Lenz, R. Patient reported outcomes in patients with chronic migraine receiving placebo or erenumab (amg 334) in a phase 2, randomized, double blind study. Neurology 2017, 88, P2-167.

23. Tepper, S.; Widnell, K.; Dolezil, D.; Ashina, M.; Reuter, U.; Brandes, J.L.; Silberstein, S.; Winner, P.; Leonardi, D.; Mikol, D. Evaluating the efficacy and safety of erenumab (amg 334) in chronic migraine prevention in a phase 2 randomized, double-blind, placebo-controlled study. Schmerz 2017, 31, S65. Available online: https://link.springer.com/article/10.1007/s00482-017-0249-3 (accessed on 17 July 2019).

24. Tepper, S.; Widnell, K.; Dolezil, D.; Ashina, M.; Reuter, U.; Lewis Brandes, J.; Silberstein, S.; Winner, P.; Leonardi, D.; Mikol, D. Evaluating the efficacy and safety of erenumab (amg 334) in chronic migraine prevention in a phase 2 randomized, double-blind, placebo-controlled study. Neurology 2017, 88, S16. Available online: https:/n.neurology.org/content/88/16_Supplement/S52.002 (accessed on 17 July 2019).

25. Tepper, S.J.; Dolezil, D.; Ashina, M.; Reuter, U.; Brandes, J.L.; Silberstein, S.D.; Winner, P.; Leonardi, D.K.; Mikol, D.D. A phase 2 randomized, double-blind, placebo-controlled study to evaluate the efficacy and safety of erenumab (amg 334) in chronic migraine prevention. Headache 2017, 57, 130.

26. Aurora, S.; Zhang, Q.; Stauffer, V. Galcanezumab effects in adult patients with episodic or chronic migraine are persistent: Data from three phase 3, randomized, double-blind, placebo-controlled evolve-1, evolve-2, and regain studies. Cephalalgia 2018, 38, 50-51.

27. Aurora, S.K.; Zhang, Q.; Stauffer, V.L. Persistence of effect of galcanezumab in patients with episodic or chronic migraine: Phase 3, randomized, double-blind, placebocontrolled evolve-1, evolve-2 and regain studies. J. Headache Pain 2018, 19. Available online: https://thejournalofheadacheandpain.biomedcentral. com/articles/10.1186/s10194-018-0951-2 (accessed on 17 July 2019). 
28. Aurora, S.K.; Zhang, Q.; Stauffer, V.L.; Daniele, M.I. Persistence of effect of galcanezumab in patients with episodic or chronic migraine: Phase3, randomized, double-blind, placebo-controlled evolve-1, evolve-2 and regain studies. Postgrad. Med. 2018, 130,79-80. Available online: https:/www.tandfonline.com/doi/full/10. 1080/00325481.2018.1512253 (accessed on 17 July 2019).

29. Depre, C.; Antalik, L.; Starling, A.; Koren, M.; Eisele, O.; Mikol, D.D. A randomised, double-blind, placebo-controlled study of erenumab safety in patients with stable angina. J. Headache Pain 2018, 19. Available online: https://thejournalofheadacheandpain.biomedcentral.com/articles/10.1186/s10194-018-09000 (accessed on 17 July 2019).

30. Depre, C.; Antalik, L.; Starling, A.J.; Koren, M.; Eisele, O.; Mikol, D. A randomized, double-blind, placebo-controlled study of erenumab safety in patients with stable angina. Headache 2018, 58, 177. Available online: https://headachejournal.onlinelibrary.wiley.com/doi/epdf/10.1111/head.13306 (accessed on 17 July 2019). [CrossRef]

31. Dolezil, D.; Klatt, J.; Cheng, S.; Zhang, F.; Wen, S.; Ritter, S.; Mikol, D.D. Efficacy of erenumab in patients with chronic migraine achieving $\geq 50 \%$ response: Subgroup analysis of a double-blind, randomised study. J. Headache Pain 2018, 19. Available online: https://thejournalofheadacheandpain.biomedcentral.com/articles/ 10.1186/s10194-018-0900-0 (accessed on 17 July 2019).

32. Dolezil, D.; Klatt, J.; Cheng, S.; Zhang, F.; Wen, S.; RItter, S.; Mikol, D.D. Efficacy of erenumab in patients with chronic migraine achieving $>50 \%$ response: Subgroup analysis of a double-blind, randomised study. Cephalalgia 2018, 38, 92-93. Available online: https://journals.sagepub.com/doi/full/10.1177/0333102418789865 (accessed on 17 July 2019).

33. Lanteri-Minet, M.; Buse, D.C.; Starling, A.; Ailani, J.; Zhang, F.; Wen, S.; Bilitou, A.; Desai, P.; Cheng, S.; Klatt, J.; et al. Patient-reported outcomes in chronic migraine patients with prior prophylactic treatment failure receiving placebo or erenumab: Subgroup analysis of a pivotal randomised study. Cephalalgia 2018, 38, 49-50. Available online: https://journals.sagepub.com/doi/full/10.1177/0333102418789865 (accessed on 17 July 2019).

34. Lanteri-Minet, M.; Buse, D.C.; Starling, A.J.; Ailani, J.; Zhang, F.; Wen, S.; Bilitou, A.; Desai, P.; Cheng, S.; Klatt, J.; et al. Patient-reported outcomes in chronic migraine patients with prior prophylactic treatment failure receiving placebo or erenumab: Subgroup analysis of a pivotal randomized study. Headache 2018, 58, 170-171. Available online: https://headachejournal.onlinelibrary.wiley.com/doi/epdf/10.1111/head.13306 (accessed on 17 July 2019).

35. Lipton, R.B.; Saper, J.; Ashina, M.; Biondi, D.; Bhattacharya, S.; Hirman, J.; Schaeffler, B.; Cady, R. A phase 3 , randomized, double-blind, placebo-controlled study to evaluate the efficacy and safety of eptinezumab for the preventive treatment of chronic migraine: Results of the promise-2 (prevention of migraine via intravenous eptinezumab safety and efficacy 2) trial. Neurology 2018, 90, 2193-2194.

36. Nagy, A.J.; Pearlman, E.; Ruff, D.; Day, K.; Aurora, S.K.; Rosen, N. 100\% response rate to galcanezumab in patients with episodic migraine: Randomized, double-blind, placebo-controlled studies. Cephalalgia 2018, 38, 63-64. Available online: https://journals.sagepub.com/doi/full/10.1177/0333102418789865 (accessed on 17 July 2019).

37. Nagy, A.J.; Pearlman, E.; Ruff, D.; Day, K.; Rosen, N. 100\% response rate to galcanezumab in patients with episodic migraine: Randomized, double-blind, placebo-controlled studies. J. Headache Pain 2018, 19. Available online: https:/thejournalofheadacheandpain.biomedcentral.com/articles/10.1186/s10194-018-09000 (accessed on 17 July 2019).

38. Nichols, R.M.; Ruff, D.; Pearlman, E.; Aurora, S.K. Analysis of initial non responders to galcanezumab in patients with episodic or chronic migraine: Results from the evolve-1, evolve-2, and regain randomized, double-blind, placebo-controlled trials. J. Headache Pain 2018, 19. Available online: https:/thejournalofheadacheandpain.biomedcentral.com/articles/10.1186/s10194-018-0900-0 (accessed on 17 July 2019).

39. Dodick, D.W.; Goadsby, P.J.; Silberstein, S.D.; Lipton, R.B.; Olesen, J.; Ashina, M.; Wilks, K.; Kudrow, D.; Kroll, R.; Kohrman, B.; et al. Safety and efficacy of ALD403, an antibody to calcitonin gene-related peptide, for the prevention of frequent episodic migraine: A randomised, double-blind, placebo-controlled, exploratory phase 2 trial. Lancet Neurol. 2014, 13, 1100-1107. [CrossRef] 
40. Goadsby, P.J.; Reuter, U.; Hallström, Y.; Broessner, G.; Bonner, J.H.; Zhang, F.; Sapra, S.; Picard, H.; Mikol, D.D.; Lenz, R.A. A Controlled Trial of Erenumab for Episodic Migraine. New Engl. J. Med. 2017, 377, 2123-2132. [CrossRef] [PubMed]

41. Sun, H.; Dodick, D.W.; Silberstein, S.; Goadsby, P.J.; Reuter, U.; Ashina, M.; Saper, J.; Cady, R.; Chon, Y.; Dietrich, J.; et al. Safety and efficacy of AMG 334 for prevention of episodic migraine: A randomised, double-blind, placebo-controlled, phase 2 trial. Lancet Neurol. 2016, 15, 382-390. [CrossRef]

42. Tepper, S.; Ashina, M.; Reuter, U.; Brandes, J.L.; Doležil, D.; Silberstein, S.; Winner, P.; Leonardi, D.; Mikol, D.; Lenz, R. Safety and efficacy of erenumab for preventive treatment of chronic migraine: A randomised, double-blind, placebo-controlled phase 2 trial. Lancet Neurol. 2017, 16, 425-434. [CrossRef]

43. Ashina, M.; Tepper, S.; Brandes, J.L.; Reuter, U.; Boudreau, G.; Dolezil, D.; Cheng, S.; Zhang, F.; Lenz, R.; Klatt, J.; et al. Efficacy and safety of erenumab (AMG334) in chronic migraine patients with prior preventive treatment failure: A subgroup analysis of a randomized, double-blind, placebo-controlled study. Cephalalgia 2018, 38, 1611-1621. [CrossRef] [PubMed]

44. Ashina, M.; Dodick, D.; Goadsby, P.J.; Reuter, U.; Silberstein, S.; Zhang, F.; Gage, J.R.; Cheng, S.; Mikol, D.D.; Lenz, R.A. Erenumab (amg 334) in episodic migraine: Interim analysis of an ongoing open-label study. Neurology 2017, 89, 1237-1243. [CrossRef] [PubMed]

45. Dodick, D.W.; Ashina, M.; Brandes, J.L.; Kudrow, D.; Lantéri-Minet, M.; Osipova, V.; Palmer, K.; Picard, H.; Mikol, D.D.; A Lenz, R. ARISE: A Phase 3 randomized trial of erenumab for episodic migraine. Cephalalgia 2018, 38, 1026-1037. [CrossRef] [PubMed]

46. Dodick, D.W.; Silberstein, S.D.; E Bigal, M.; Yeung, P.P.; Goadsby, P.J.; Blankenbiller, T.; Grozinski-Wolff, M.; Yang, R.; Ma, Y.; Aycardi, E. Effect of Fremanezumab Compared With Placebo for Prevention of Episodic Migraine: A Randomized Clinical Trial. JAMA 2018, 319, 1999-2008. [CrossRef]

47. Silberstein, S.D.; Dodick, D.W.; Bigal, M.E.; Yeung, P.P.; Goadsby, P.J.; Blankenbiller, T.; Grozinski-Wolff, M.; Yang, R.; Ma, Y.; Aycardi, E. Fremanezumab for the Preventive Treatment of Chronic Migraine. New Engl. J. Med. 2017, 377, 2113-2122. [CrossRef]

48. Li, T.; Aycardi, E.; Cohen, J.M.; Dodick, D.W.; Newman, L.C.; Bigal, M.E.; Yang, R. Fremanezumab as Add-On Treatment for Patients Treated With Other Migraine Preventive Medicines. Headache J. Head Face Pain 2017, $57,1375-1384$.

49. E Bigal, M.; Edvinsson, L.; Rapoport, A.M.; Lipton, R.B.; Spierings, E.L.H.; Diener, H.-C.; Burstein, R.; Loupe, P.S.; Ma, Y.; Yang, R.; et al. Safety, tolerability, and efficacy of TEV-48125 for preventive treatment of chronic migraine: A multicentre, randomised, double-blind, placebo-controlled, phase 2b study. Lancet Neurol. 2015, 14, 1091-1100. [CrossRef]

50. Bigal, M.E.; Dodick, D.W.; Krymchantowski, A.V.; VanderPluym, J.H.; Tepper, S.J.; Aycardi, E.; Loupe, P.S.; Ma, Y.; Goadsby, P.J. Tev-48125 for the preventive treatment of chronic migraine: Efficacy at early time points. Neurology 2016, 87, 41-48. [CrossRef]

51. Singh, R.B.H.; Aycardi, E.; E Bigal, M.; Loupe, P.S.; McDonald, M.; Dodick, D.W. Sustained reductions in migraine days, moderate-to-severe headache days and days with acute medication use for HFEM and CM patients taking fremanezumab: Post-hoc analyses from phase 2 trials. Cephalalgia 2018, 39, 52-60. [CrossRef] [PubMed]

52. Stauffer, V.L.; Dodick, D.W.; Zhang, Q.; Carter, J.N.; Ailani, J.; Conley, R.R. Evaluation of galcanezumab for the prevention of episodic migraine: The evolve-1 randomized clinical trial. JAMA Neurol. 2018, 75, 1080-1088. [CrossRef] [PubMed]

53. Oakes, T.M.M.; Skljarevski, V.; Zhang, Q.; Kielbasa, W.; E Hodsdon, M.; Detke, H.C.; Camporeale, A.; Saper, J.R.; Skljarevsuki, V. Safety of galcanezumab in patients with episodic migraine: A randomized placebo-controlled dose-ranging Phase 2b study. Cephalalgia 2018, 38, 1015-1025. [CrossRef] [PubMed]

54. Skljarevski, V.; Matharu, M.; A Millen, B.; Ossipov, M.H.; Kim, B.-K.; Yang, J.Y. Efficacy and safety of galcanezumab for the prevention of episodic migraine: Results of the EVOLVE-2 Phase 3 randomized controlled clinical trial. Cephalalgia 2018, 38, 1442-1454. [CrossRef] [PubMed]

55. Dodick, D.W.; Goadsby, P.J.; Spierings, E.L.H.; Scherer, J.C.; Sweeney, S.P.; Grayzel, D.S. Safety and efficacy of LY2951742, a monoclonal antibody to calcitonin gene-related peptide, for the prevention of migraine: A phase 2, randomised, double-blind, placebo-controlled study. Lancet Neurol. 2014, 13, 885-892. [CrossRef] 
56. Skljarevski, V.; Oakes, T.M.; Zhang, Q.; Ferguson, M.B.; Martinez, J.; Camporeale, A.; Johnson, K.W.; Shan, Q.; Carter, J.; Schacht, A.; et al. Effect of different doses of galcanezumab vs placebo for episodic migraine prevention: A randomized clinical trial. JAMA Neurol. 2018, 75, 187-193. [CrossRef]

57. Schwedt, T.; Reuter, U.; Tepper, S.; Ashina, M.; Kudrow, D.; Broessner, G.; Boudreau, G.P.; McAllister, P.; $\mathrm{Vu}, \mathrm{T}$; Z Zhang, F.; et al. Early onset of efficacy with erenumab in patients with episodic and chronic migraine. J. Headache Pain 2018, 19, 92. [CrossRef]

58. Reuter, U.; Goadsby, P.J.; Lanteri-Minet, M.; Wen, S.; Hours-Zesiger, P.; Ferrari, M.D.; Klatt, J. Efficacy and tolerability of erenumab in patients with episodic migraine in whom two-to-four previous preventive treatments were unsuccessful: A randomised, double-blind, placebo-controlled, phase 3b study. Lancet 2018, 392, 2280-2287. [CrossRef]

59. Silberstein, S.D.; Rapoport, A.M.; Loupe, P.S.; Aycardi, E.; McDonald, M.; Yang, R.; Bigal, M.E. The effect of beginning treatment with fremanezumab on headache and associated symptoms in the randomized phase 2 study of high frequency episodic migraine: Post-hoc analyses on the first 3 weeks of treatment. Headache 2019, 59, 383-393. [CrossRef]

60. Rosen, N.; Pearlman, E.; Ruff, D.; Day, K.; Nagy, A.J. 100\% Response Rate to Galcanezumab in Patients With Episodic Migraine: A Post Hoc Analysis of the Results From Phase 3, Randomized, Double-Blind, Placebo-Controlled EVOLVE-1 and EVOLVE-2 Studies. Headache J. Head Face Pain 2018, 58, 1347-1357. [CrossRef]

61. Nichols, R.; Doty, E.; Sacco, S.; Ruff, D.; Pearlman, E.; Aurora, S.K. Analysis of Initial Nonresponders to Galcanezumab in Patients With Episodic or Chronic Migraine: Results From the EVOLVE-1, EVOLVE-2, and REGAIN Randomized, Double-Blind, Placebo-Controlled Studies. Headache J. Head Face Pain 2018, 59, 192-204. Available online: https://headachejournal.onlinelibrary.wiley.com/doi/full/10.1111/head.13443 (accessed on 17 July 2019). [CrossRef] [PubMed]

62. Detke, H.C.; Goadsby, P.J.; Wang, S.; Friedman, D.I.; Selzler, K.J.; Aurora, S.K. Galcanezumab in chronic migraine: The randomized, double-blind, placebo-controlled regain study. Neurology 2018, 91, 2211-2221. [CrossRef] [PubMed]

63. Camporeale, A.; Kudrow, D.; Sides, R.; Wang, S.; Van Dycke, A.; Selzler, K.J.; Stauffer, V.L. A phase 3, long-term, open-label safety study of Galcanezumab in patients with migraine. BMC Neurol. 2018, 18, 188. [CrossRef] [PubMed]

64. Ayer, D.W.; Skljarevski, V.; Ford, J.H.; Nyhuis, A.W.; Lipton, R.B.; Aurora, S.K. Measures of Functioning in Patients With Episodic Migraine: Findings From a Double-Blind, Randomized, Placebo-Controlled Phase 2b Trial With Galcanezumab. Headache J. Head Face Pain 2018, 58, 1225-1235. [CrossRef] [PubMed]

65. Zhu, Y.; Liu, Y.; Zhao, J.; Han, Q.; Liu, L.; Shen, X. The efficacy and safety of calcitonin gene-related peptide monoclonal antibody for episodic migraine: A meta-analysis. Neurol. Sci. 2018, 39, 2097-2106. [CrossRef] [PubMed]

66. Han, L.; Liu, Y.; Xiong, H.; Hong, P. CGRP monoclonal antibody for preventive treatment of chronic migraine: An update of meta-analysis. Brain Behav. 2019, 9, e01215. [CrossRef] [PubMed]

67. Hong, P.; Wu, X.; Liu, Y.; Information, P.E.K.F.C. Calcitonin gene-related peptide monoclonal antibody for preventive treatment of episodic migraine: A meta analysis. Clin. Neurol. Neurosurg. 2017, 154, 74-78. [CrossRef] [PubMed]

68. Hou, M.; Xing, H.; Cai, Y.; Li, B.; Wang, X.; Li, P.; Hu, X.; Chen, J. The effect and safety of monoclonal antibodies to calcitonin gene-related peptide and its receptor on migraine: A systematic review and meta-analysis. J. Headache Pain 2017, 18, 42. [CrossRef]

69. Lin, Y.; Chen, D.; Xu, D.; Liu, L. Efficacy and safety of erenumab in the preventive treatment of migraine in adults: A systematic review. Chin. J. Contemp. Neurol. Neurosurg. 2018, 18, 647-653.

70. Monteith, D.; Collins, E.C.; Vandermeulen, C.; van Hecken, A.; Raddad, E.; Scherer, J.C.; Grayzel, D.; Schuetz, T.J.; de Hoon, J. Safety, Tolerability, Pharmacokinetics, and Pharmacodynamics of the CGRP Binding Monoclonal Antibody LY2951742 (Galcanezumab) in Healthy Volunteers. Front. Pharm. 2017, 8, 740. [CrossRef]

71. Kaplon, H.; Reichert, J.M. Antibodies to watch in 2018. MABS 2018, 10, 183-203. [CrossRef] [PubMed]

72. Reuter, U. A Review of Monoclonal Antibody Therapies and Other Preventative Treatments in Migraine. Headache J. Head Face Pain 2018, 58, 48-59. [CrossRef] [PubMed] 
73. Cohen-Barak, O.; Weiss, S.; Rasamoelisolo, M.; Faulhaber, N.; Yeung, P.P.; Loupe, P.S.; Yoon, E.; Gandhi, M.D.; Spiegelstein, O.; Aycardi, E. A phase 1 study to assess the pharmacokinetics, safety, and tolerability of fremanezumab doses $(225 \mathrm{mg}, 675 \mathrm{mg}$ and $900 \mathrm{mg}$ ) in Japanese and Caucasian healthy subjects. Cephalalgia 2018, 38, 1960-1971. [CrossRef] [PubMed]

74. De Hoon, J.; van Hecken, A.; Vandermeulen, C.; Yan, L.; Smith, B.; Chen, J.S.; Bautista, E.; Hamilton, L.; Waksman, J.; Vu, T.; et al. Phase i, randomized, double-blind, placebo-controlled, single-dose, and multiple-dose studies of erenumab in healthy subjects and patients with migraine. Clin Pharm. 2018, 103, 815-825. [CrossRef] [PubMed]

75. Kao, C.-C.; Lin, Y.-S.; Chu, H.-C.; Fang, T.-C.; Wu, M.-S.; Kang, Y.-N. Association of Renal Function and Direct-Acting Antiviral Agents for HCV: A Network Meta-Analysis. J. Clin. Med. 2018, 7, 314. [CrossRef] [PubMed]

76. Ku, F.-Y.; Wu, C.-C.; Hsiao, Y.-W.; Kang, Y.-N. Association of sperm source with miscarriage and take-home baby after ICSI in cryptozoospermia: A meta-analysis of testicular and ejaculated sperm. Andrology 2018, 6, 882-889. [CrossRef] [PubMed]

77. Lin, T.M.; Chi, J.E.; Chang, C.C.; Kang, Y.N. Do etoricoxib and indometacin have similar effects and safety for gouty arthritis? A meta-analysis of randomized controlled trials. J. Pain Res. 2019, 12, 83-91. [CrossRef]

78. Liao, A.H.-W.; Lin, Y.-C.; Bai, C.-H.; Chen, C.-Y. Optimal dose of succinylcholine for laryngeal mask airway insertion: Systematic review, meta-analysis and metaregression of randomised control trials. BMJ Open 2017, 7, e014274. [CrossRef]

79. Lin, E.-Y.; Kuo, Y.-K.; Kang, Y.-N. Effects of three common lumbar interbody fusion procedures for degenerative disc disease: A network meta-analysis of prospective studies. Int. J. Surg. 2018, 60, 224-230. [CrossRef]

80. Hutton, B.; Salanti, G.; Caldwell, D.M.; Chaimani, A.; Schmid, C.H.; Cameron, C.; Ioannidis, J.P.; Straus, S.; Thorlund, K.; Jansen, J.P.; et al. The PRISMA Extension Statement for Reporting of Systematic Reviews Incorporating Network Meta-analyses of Health Care Interventions: Checklist and Explanations. Ann. Intern. Med. 2015, 162, 777-784. [CrossRef] 